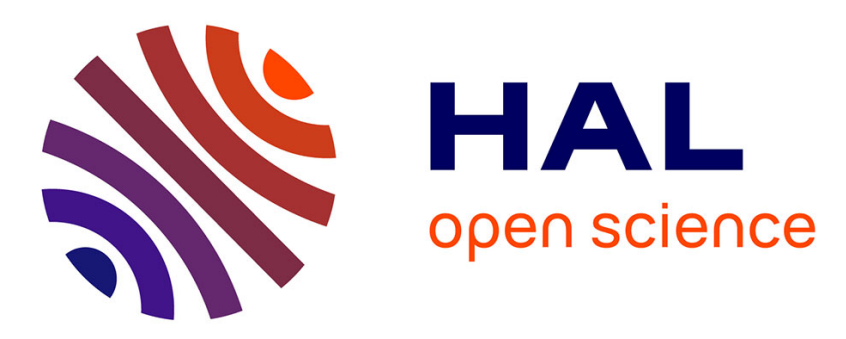

\title{
Effect Of Parasitic Capacitance on GMI Magnetic Sensor Performance
}

Sébastien Saez, Basile Dufay, Christophe Dolabdjian, A. Yelon, D. Menard

\section{To cite this version:}

Sébastien Saez, Basile Dufay, Christophe Dolabdjian, A. Yelon, D. Menard. Effect Of Parasitic Capacitance on GMI Magnetic Sensor Performance. Key Engineering Materials, 2013, pp.49(1), 124-127. hal-00988087

\section{HAL Id: hal-00988087 https://hal.science/hal-00988087}

Submitted on 7 May 2014

HAL is a multi-disciplinary open access archive for the deposit and dissemination of scientific research documents, whether they are published or not. The documents may come from teaching and research institutions in France or abroad, or from public or private research centers.
L'archive ouverte pluridisciplinaire HAL, est destinée au dépôt et à la diffusion de documents scientifiques de niveau recherche, publiés ou non, émanant des établissements d'enseignement et de recherche français ou étrangers, des laboratoires publics ou privés. 


\title{
Effect of Parasitic Capacitance on GMI Magnetic Sensor Performance
}

\author{
S.Saez ${ }^{1, a}$, B.Dufay ${ }^{1,2, b}$, C.Dolabdjian ${ }^{1, \mathrm{c}}$, A.Yelon $^{2, \mathrm{~d}}$ and D.Menard ${ }^{2, \mathrm{e}}$
}

${ }^{1}$ GREYC UMR 6072 and Université de Caen Basse-Normandie and ENSICAEN, France, 14050 Caen Cedex

\author{
${ }^{2}$ École Polytechnique de Montréal, département de génie physique \& regroupement québécois des \\ matériaux de pointe, Montréal, Québec, Canada H3C3A7 \\ asebastien.saez@unicaen.fr, bbasile.dufay@unicaen.fr, ${ }^{\mathrm{c}} \mathrm{christophe.dolabdjian@unicaen.fr,}$ \\ dArthur.Yelon@polymtl.ca, ${ }^{e}$ david.menard@polymtl.ca
}

Keywords: Magnetometer, low noise sensor, GMI.

\begin{abstract}
Magnetic sensors based on GMI devices are the subject of intensive research, as they appear promising for magnetometry applications. Performances of GMI magnetometers are often limited by the noise of the electronic setup. Thus, the present challenge is to increase the GMI device sensitivity (expressed in $\mathrm{V} / \mathrm{T}$ ) in order to decrease the equivalent magnetic noise of the system. In our previous work, we showed that the use of a pick-up coil in an off-diagonal configuration improves the magnetic sensor sensitivity and offers a promising approach for developing an inexpensive magnetometer with sub-pT/ $\sqrt{ } \mathrm{Hz}$ equivalent magnetic noise levels. Ideally, the use of a coil increases the sensitivity linearly as a function of the number of turns. However, this effect is reduced by the parasitic capacitance of the coil. This affects the device sensitivity, noise level and system performance. The parasitic capacitance can degrade all of these, but also induces a resonance effect, which can help to optimize magnetometer sensitivity, and thus, its noise level. We analyze the effects of the parasitic capacitance on the system (sensitivity and noise) and propose optimization routes. We have obtained sensor sensitivity as high as $700 \mathrm{fT} / \sqrt{ } \mathrm{Hz}$.
\end{abstract}

\section{Introduction}

High-sensitivity magnetometry is a major research issue for many applications (NDE, biomagnetism, military, etc.). These require low-cost magnetometers with wide bandwidth, equivalent magnetic noise below $1 \mathrm{pT} / \sqrt{\mathrm{Hz}}$ close to $1 \mathrm{~Hz}$, operating at room temperature. GMI magnetometers are good candidates to meet this challenge, since their theoretical noise level is about $10 \mathrm{fT} / \sqrt{ } \mathrm{Hz}$ [1]. However, existing devices are limited by their electronics to approximately $3 \mathrm{pT} / \sqrt{\mathrm{Hz}}[2]$.

The equivalent magnetic noise of a magnetic sensor (in $\mathrm{T} / \sqrt{\mathrm{Hz}}$ ), $b_{n}$, may be described by the simple equation $b_{n}{ }^{2}=b_{n s}{ }^{2}+e_{n}{ }^{2} / T_{r}{ }^{2}$, where $b_{n s}$ is the equivalent magnetic noise of the sensor (in T/ $\sqrt{\mathrm{Hz}}$ ), $e_{n}$ is the output voltage noise of the electronic setup used (in $\mathrm{V} / \sqrt{\mathrm{Hz}}$ ), and $T_{r}$ is the output sensitivity of the magnetic sensor (in V/T). For GMI magnetic sensors, experiments usually show that $b_{n} \approx e_{n} / T_{r}$. The reduction of electronic noise is difficult, since the electronic setup is often optimized. In this case, it is necessary to increase the intrinsic device sensitivity in order to improve system performance. In response to this problem, we have demonstrated [3.4] the interest of strongly-coupled thin pick-up coils associated with the GMI sensor wire. This configuration is often used, and described as off-diagonal GMI [5] or orthogonal flux-gate in the fundamental mode [6]. Here, we pursue this approach, and discuss the limitations and opportunities associated with this arrangement. In particular, we treat the effect of parasitic capacitance.

The paper is organized as follows. First, we recall the sensing element configuration and the principle of its implementation. The model of sensing element magnetic response, in the presence of parasitic capacitance, is then presented. We conclude after a discussion of the effect of this capacitance on intrinsic sensitivity. 


\section{The sensing element and its principle}

The sensing element used is a common off-diagonal GMI configuration. As shown in Fig. 1a,. $l$ and $l_{c}$ are the lengths of the GMI wire and of the pick-up coil. The coil consists of three independent layers, of 600 turns each. By connecting them in series, it is easy to modify the number of turns, $N(=600,1200$ or 1800$)$, without changing the experimental conditions for the magnetic wire. The inner layer is wound directly on the CoFeSiB amorphous ferromagnetic wire, $100 \mu \mathrm{m}$ in diameter, called c3 in [7], chosen from a set of samples. It represents a good compromise between high sensitivity and robustness.

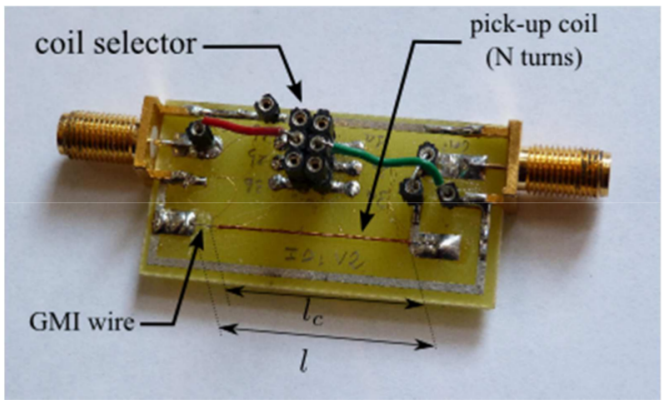

a)

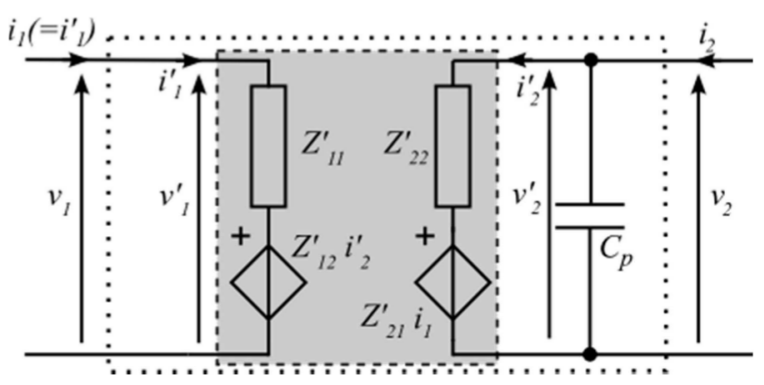

b)

Figure 1: a) Off-diagonal GMI sensing element. b) two-port network electric model. Here, the magnetic response elements, $Z_{i j}^{\prime}$, represent the ideal behavior without parasitic capacitance, and the parasitic capacitance, $C_{p}$, is shown separately.

As we have shown elsewhere [3, 4], the best magnetic sensitivity is obtained when an rf current, of amplitude $I_{a c}$ and frequency $f_{p}$, is applied to the wire, and the output signal is the open circuit voltage of the pick-up coil. The rf voltage appearing across the coil is ideally amplified at high frequency with gain $G_{1}$, and sensed by a diode peak-detector with gain $G_{p d}$, which shifts the signal, $v_{S}(t)$, to low frequency. This image of the small sensed applied magnetic field, $b(t)$, is amplified, with gain $G_{2}$, and filtered, classically. From an electrical point of view, the off-diagonal GMI can be modeled as a two-port network, described by its external magnetic field-dependent impedance matrix $\left[Z_{i j}\right]$. The $Z_{21}$ term allows to describe the magnetic response of this system.

Considering a magnetic static working point $B_{0}, Z_{21}$ can be obtained from a first order Taylor series: $\quad Z_{21}\left(B_{0}+b(t)\right)=Z_{21}\left(B_{0}\right)+\frac{\partial Z_{21}}{\partial B}\left(B_{0}\right) b(t) . \quad$ Then, $\quad v_{s}=T_{r} b(t) \quad$ where $T_{r}\left(=I_{a c} G_{1} G_{p d} G_{2} \frac{\partial Z_{21}}{\partial B}\left(B_{0}\right)\right)$ is the output sensitivity of the magnetic sensor (in V/T) and $\frac{\partial Z_{21}}{\partial B}\left(B_{0}\right)$ is the intrinsic sensitivity of the sensing element in the chosen set-up (in $\Omega / T$ ).

\section{Magnetic response of the sensing element}

In the past, modeling of the system has not taken the parasitic capacitance into account. Then, modeling of the impedance matrix is directly connected to the model of the magnetic device via the surface impedance $\left[\zeta_{s}\right][8]$. This impedance can be considered as purely magnetic and written $\left[Z_{i j}^{\prime}\right]$. In our case, the system consists of the impedance matrix $\left[Z_{i j}^{\prime}\right]$ coupled with a capacitor $C_{p}$ in parallel with the output port (cf. Fig. 1b). The $Z_{21}$ term depends upon the magnetic terms $Z_{2 I}^{\prime}$ and $Z_{22}{ }_{22}$ and capacitance $C_{p}$ as

$$
Z_{21}=\left.\frac{v_{2}}{i_{1}}\right|_{i_{2}=0}=\frac{Z_{21}^{\prime}}{1+j 2 \pi f_{p} Z_{22}^{\prime} C_{p}}
$$

By using the relationship between electrical signals, in the purely magnetic two-port, $\left(i{ }_{1}, i_{2}{ }_{2}, v^{\prime}{ }_{1}\right.$, $\left.v^{\prime}{ }^{\prime}\right)$, and the electric and magnetic fields appearing at the ferromagnetic wire surface $[9,10]$, terms $Z^{\prime}{ }_{21}$ and $Z_{22}^{\prime}$ can be determined from the magnetic, $Z_{M}$, and the non-magnetic, $Z_{N}$, impedances and 
the angle $\theta_{M}$, which characterizes the static magnetization direction. This yields: $Z_{21}^{\prime}=N\left(Z_{N}-Z_{M}\right) \sin \theta_{M} \cos \theta_{M}$, and $Z_{22}^{\prime}=\frac{2 \pi a N^{2}}{l_{c}}\left(Z_{N} \cos ^{2} \theta_{M}+Z_{M} \sin ^{2} \theta_{M}\right)$. Then, $Z_{21}$ may be written as:

$$
Z_{21}=\frac{N\left(Z_{N}-Z_{M}\right) \sin \theta_{M} \cos \theta_{M}}{1+j \frac{2 \pi a N^{2}}{l_{C}}\left(Z_{N} \cos ^{2} \theta_{M}+Z_{M} \sin ^{2} \theta_{M}\right) C_{p} \omega_{p}}
$$

Figure 2 shows good agreement between the theoretical expression and measured value of $Z_{21}^{\prime}$. We note that Eq. (2) correctly describes the inversion of the the imaginary part of $Z_{21}$ between $500 \mathrm{kHz}$ and $1 \mathrm{MHz}$, using -0.4 Oe bias field as the working point.
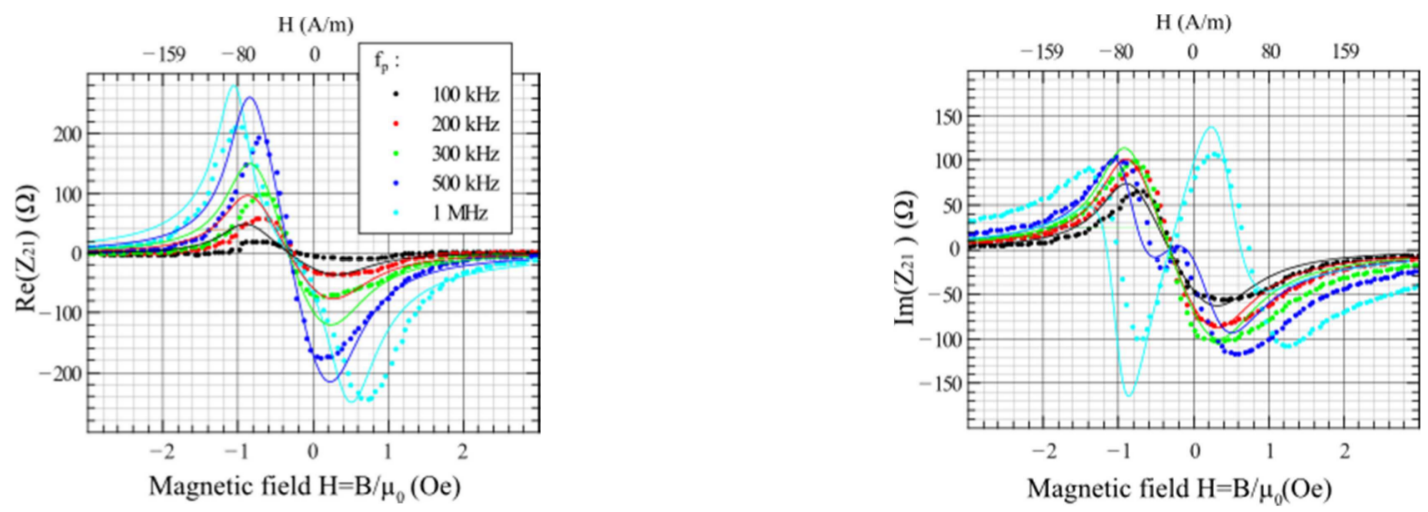

Figure 2: Real and imaginary parts of $Z_{21}$, measured (solid) and computed (dotted) using Eq. (2) and parameters reported in [7]) for five different frequencies, $f_{p}$.

\section{Optimization of the sensitivity by parasitic capacitance adjustment}

The good agreement between theory and experiment is also true for the sensitivity, as shown in Fig. 3a. Without $C_{p}$, the intrinsic sensitivity should increase linearly with $N$ and with $f_{p}$. The decrease of the sensitivity at high frequency, observed in practice, is explained by the presence of parasitic capacitance in the model. The peak in intrinsic sensitivity corresponds to RLC resonance.

Figure $3 \mathrm{~b}$ shows intrinsic sensitivity behavior as a function of $C_{p}$. It suggests how sensitivity may be optimized. If the capacity is too high, the sensitivity decreases drastically. It should be noted that, because of this, the sensitivity at $10 \mathrm{MHz}$ and 1800 turns may be less than at $1 \mathrm{MHz}$ and 600 turns, as given in figure $3 \mathrm{c}$. The presence of capacitance allows for higher sensitivity than in its absence, as shown in Fig. 4a, but eventually degrades it at high frequency.

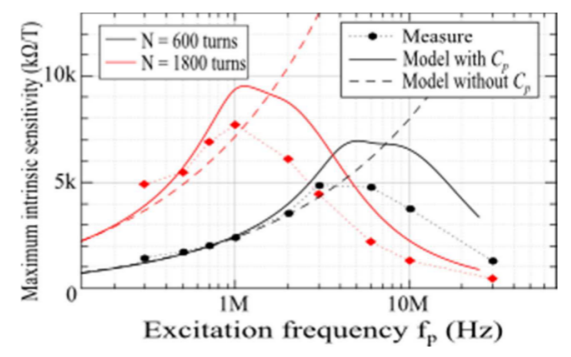

a)

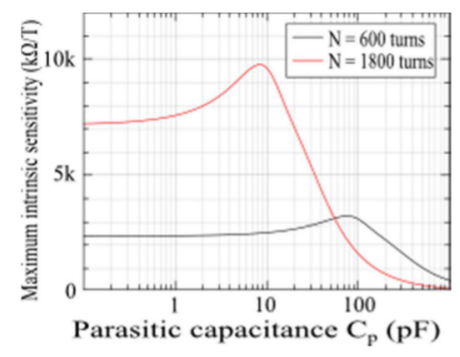

b)

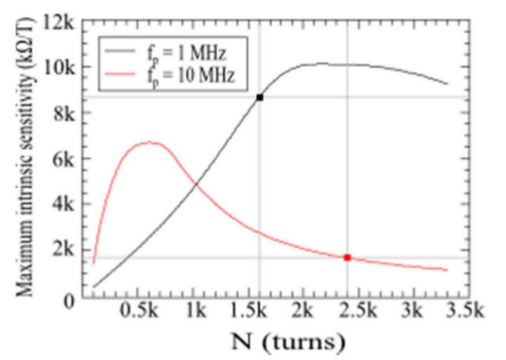

c)

Figure 3: a) Maximum intrinsic sensitivity vs. excitation frequency $f_{p}$, measured and computed for two values of $N, 600$ and 1800 . b) Maximum intrinsic sensitivity vs. parasitic capacitance value $C_{p}$ computed for two values of $N$. c) Maximum sensitivity vs. $N$ computed for 1 and $10 \mathrm{MHz}$, with $C_{p}=10 \mathrm{pF}$. The points indicate maximal intrinsic sensitivity for two examples: $f_{p}=1 \mathrm{MHz}$, $\mathrm{N}=1600$ turns, and $f_{p}=10 \mathrm{MHz}, \mathrm{N}=2400$ turns. 


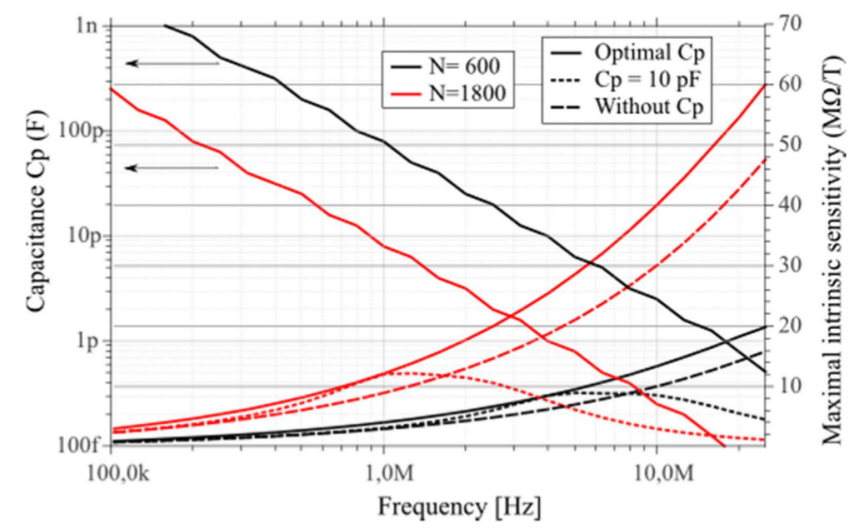

a)

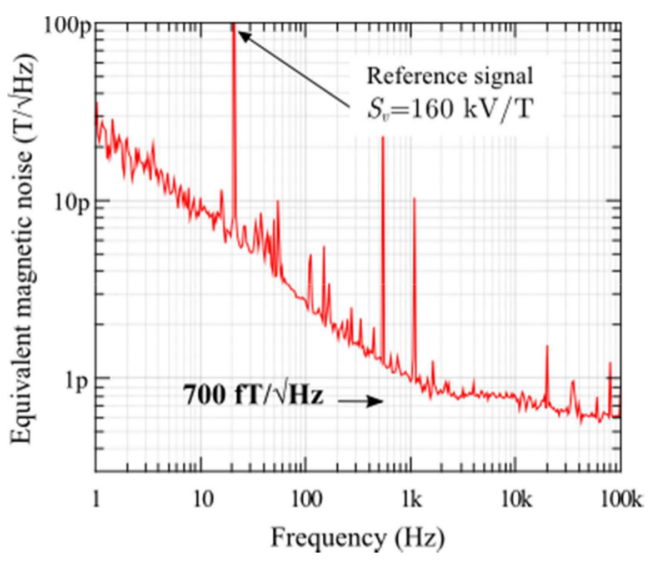

b)

Figure 4: a) Optimal capacitance value and maximal intrinsic sensitivity vs. excitation frequency for $N=600$ and 1800 , for three choices of capacitance:.at each frequency the capacitance is adapted to maximize intrinsic sensitivity (solid), the capacitance value is fixed at $10 \mathrm{pF}$ (dotted), the two-port network is ideal (no parasitic capacitance) (dashed). b).Experimental equivalent magnetic noise spectral density vs. frequency for an optimized sensor.

\section{Conclusion}

From the results presented here, it is clear that for a given value of parasitic capacitance, $C_{p}$, the sensitivity can be optimized by the proper choice of $N$, the number of turns, and $f_{p}$, the excitation frequency. However, the intrinsic sensitivity is intrinsically limited by the parasitic capacitance.. The use of this analysis give us the opportunity to design and operate such a sensor. As shown in Fig. $4 \mathrm{~b}$, it has an equivalent magnetic input sensor white noise level of $700 \mathrm{fT} / \mathrm{Hz}$ more than competitive with current commercial technologies.

\section{References}

[1] L.G.C. Melo, D. Menard, A. Yelon, L. Ding, S. Saez, C. Dolabdjian: J. Appl. Phys. (103), 033903 (2008)

[2] L. Ding, S. Saez, C. Dolabdjian, L. G. C. Melo, A. Yelon, D. Ménard: IEEE Sensors J., 9 (2), 159-168 (2009)

[3] B. Dufay, S. Saez, C. Dolabdjian, D. Seddaoui, A. Yelon, D. Ménard: Sensor Letters, 7, 334338 (2009)

[4] B. Dufay, S. Saez, C. Dolabdjian,D. Menard, A. Yelon: IEEE Sensors J., 11 (6), 1317-1324 (2011)

[5] S. Sandacci, D. Makhnovskiy, L. Panina, K. Mohri, and Y. Honkura: IEEE Trans. Mag., 40 (6), 3505-3511 (2004)

[6] E. Paperno: Sensors and Actuators A: Physical, 116 (3), 405-409 (2004)

[7] B. Dufay, S. Saez, C. Dolabdjian, D. Menard, A. Yelon: JMMM, 324 (13), 2091-2099 (2012)

[8] L. Landau, E. Lifshitz, Electrodynamics of continuous media. Pergamon Press, Oxford, 1960.

[9] D. Makhnovskiy, L. Panina, and D. Mapps: Journal of Applied Physics, 87 (9), 4804-4806, 2000

[10] D. Ménard, A. Yelon: Journal of Applied Physics, 88 (1), 379-393, 2000. 